\title{
Cultural heritage science at CNA (seville, Spain): Applications of XRF and IBA techniques to art and archaeological objects.
}

\author{
F.J. Ager ${ }^{\mathrm{a}, \mathrm{b}, *}$, MA. Respaldiza ${ }^{\mathrm{a}, \mathrm{c}, * *}$, S . S crivano ${ }^{\mathrm{a}}$, I . Ortega-Feliu ${ }^{\mathrm{a}, \mathrm{d}}$, A. Kriznar ${ }^{\mathrm{a}, \mathrm{e}}$, B. Gómez-Tubío ${ }^{\mathrm{a}, \mathrm{d}}$ \\ ${ }^{a}$ Centro Nacional de Aceleradores, (Universidad de Sevilla-CSIC-J. Andalucía), c/ Thomas A. Edison 7, 41092, Seville, Spain \\ ${ }^{\mathrm{b}}$ Departamento de Física Aplicada I. Universidad de Sevilla, c/ Virgen de África 7, 41001, Seville, Spain \\ ${ }^{\mathrm{c}}$ Departamento de Física Atómica, Molecular y Nuclear. Universidad de Sevilla, Avda. de La Reina Mercedes s/n, 41012, Seville, Spain \\ ${ }^{\mathrm{d}}$ Departamento de Física Aplicada III. Universidad de Sevilla, Camino de Los Descubrimientos, $s / n$, 41092, Seville, Spain \\ ${ }^{\text {e }}$ Departamento de Prehistoria y Arqueología. Universidad de Sevilla, c/ María de Padilla $s / n, 41004$, Seville, Spain
}

\begin{abstract}
A B S T R A C T
Keywords:

Portable XRF

IBA

Cultural heritage

Art

Archaeological objects

The use of nuclear analytical techniques has experienced an extraordinary growth in recent decades in the field of cultural heritage. Nowadays, their use in the study of objects of interest in heritage has become essential. An important effort has been made since the 90 s by the archaeometry research group of the Centro Nacional de Aceleradores, CNA (Sevilla, Spain) to develop different non-destructive analytical techniques for the study of art and archeological objects. These efforts were initially focused on the use of Ion Beam techniques (IBA) and lately in the development of portable X-Ray Fluorescence (XRF) equipment, including microbeam versions with the implementation of polycapillary lenses ( $\mu \mathrm{XRF}$ and confocal XRF).

The different methods and instrumentation developed in the past years at CNA are presented in this work and several applications illustrate the capabilities for the analysis of different types of objects: jewelry, coins, paintings, ceramics, etc. Advantages and limitations of the different techniques are shown together with examples of how the combination of several of those methods can overcome some of the limitations are presented.
\end{abstract}

\section{Introduction}

The name "cultural heritage science" usually includes all those applications of scientific techniques or methodologies to the study of all kinds of objects of interest in cultural heritage. It can be said that it is what for some time was called archaeometry in a broad sense of the word, including not only archeological objects but also all kinds of art pieces. In the last decades, this field of study has undergone a very important growth due to the need of complementing traditional typological and stylistic information with objective data about the composition, manufacturing methods and deterioration processes of a certain work of art. And not only because all this information is obviously useful before and throughout restoration or intervention tasks, but it is often crucial for authentication or in comparative studies of the work of a particular artist belonging to a certain school or artistic current, or the evolution over the years.

Nuclear non-destructive analytical techniques are particularly important in cultural heritage science due to the multielemental character and high sensitivity, which in most cases allow the analysis not only of major and minor elements, but also the analysis of trace elements down to a few ppm. In addition, objects of any size and shape can be analyzed in most cases, sampling is often unnecessary, and even some of these techniques allow in situ analysis of the art objects, making expensive and, sometimes, risky transportation unnecessary.

For some decades now, at the Centro Nacional de Aceleradores (CNA) in Seville we have been contributing to the development of instruments and methodologies for the analytical study of all types of objects and materials of interest in cultural heritage. We have placed particular emphasis on the combination of different nuclear techniques to overcome the main limitations of some of these techniques, which are related to their near-surface character and the low sensitivity of most of them for the detection of light elements. Indeed, the effective analytical depth of most of these non-destructive techniques is limited to a few hundred microns, which means that in the analysis of objects with superficial alterations, due to corrosion, wear, manufacture, etc., results may not be representative of the volumetric composition. Also, some of

\footnotetext{
* Corresponding author. C/ Thomas A. Edison 7, 41092, Seville, Spain.

** Corresponding author. C/ Thomas A. Edison 7, 41092, Seville, Spain. E-mail addresses: fjager@us.es (F.J. Ager), respaldiza@us.es (M.A. Respaldiza).
} 
these techniques are insensitive to lighter elements $(Z<13)$, so it is necessary to complete the information with more sensitive techniques.

In this work we will try to synthesize the main applications that we have been carrying out in the cultural heritage science field, showing the difficulties that the use of these techniques may pose for different types of materials (coins, jewelry, paintings, ceramics, etc.) and a possible resolution sometimes by means of the combination of several of them.

Like all interdisciplinary work, the approach of the objectives when performing the analysis of the different objects is a crucial step and it can be done only with a close collaboration with specialists from the different humanistic areas.

\section{Experimental facilities}

The following is a brief description of the latest equipment developed by the authors and some of the equipment regularly used in our applications in the field of cultural heritage science.

\subsection{Portable $X R F$ and $\mu X R F$ setups}

Over the years, we have been developing different portable XRF equipment using the most advanced technology available at that time. The first portable XRF units were heavier and bulkier, and included detectors cooled by $\mathrm{LN}_{2}$. Later, they were replaced by Peltier-cooled detectors, which, together with the reduction in the size of the X-ray tubes, led to the development of very light equipment that can be placed in robotic arms for safe and comfortable use at high positions.

The $\mu$ XRF setup and the details of the measuring head are shown in Fig. 1 (Scrivano et al., 2017b). The portable $\mu$ XRF setup consists of a three-axis motor stage from STANDA Ltd. ( $\sim 1 \mu \mathrm{m}$ full-step resolution) coupled with a horizontal platform and a fixed measuring head

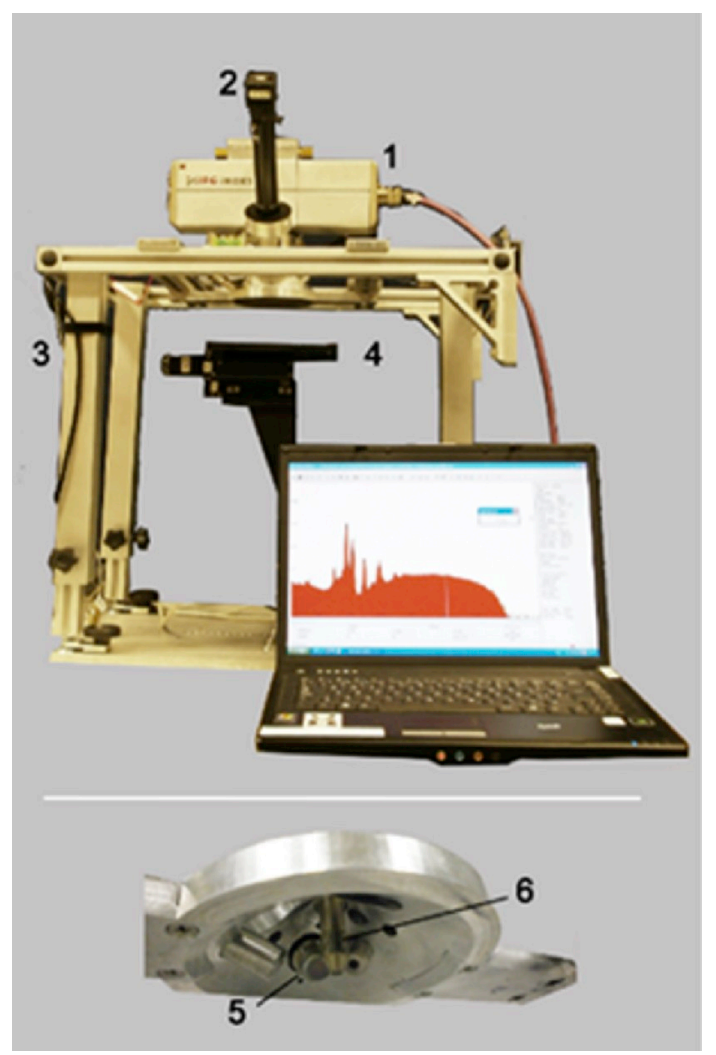

Fig. 1. The $\mu \mathrm{XRF}$ transportable spectrometer of the CNA laboratory. (1) X-ray tube, (2) microscope and CCD camera, (3) telescopic tripod support, (4) three axis-motorized sample holder, (5) SDD detector, (6) polycapillary lens. mounted on a horizontal telescopic tripod structure. The measuring head consists of a low power $(30 \mathrm{~W})$ air-cooled microfocus X-ray tube (iMOXS, IfG)(IfG, 2008) with Rh anode $(50 \mathrm{kV}, 0.6 \mathrm{~mA})$. The microbeam spot size is $30 \mu \mathrm{m}$ (FWHM) on the sample. A silicon drift detector by Amptek with a $25 \mathrm{~mm}^{2}$ active area, $500 \mu \mathrm{m}$ thick crystal and with a resolution of about $127 \mathrm{eV}$ FWHM at $5.9 \mathrm{keV}$. An optical microscope coupled with a CCD camera allows for the investigation of small areas (2.5X-10X) whereas a HD camera can be used to have a view of the whole sample still maintaining good level of detail. The working distance $(10 \mathrm{~mm})$ between the polycapillary exit and the sample is controlled by two micro laser diodes. All components of the spectrometer are mounted into a frame to create a tight fitting $90^{\circ} / 45^{\circ}$ XRF excitation/detection geometry ensuring good stability.

\subsection{Portable confocal $\mu X R F$ setup}

The confocal micro X-Ray fluorescence measuring head (Fig. 2) (Laclavetine, 2015; Laclavetine et al., 2016) consists of a micro-focus Xray source (IMOXS, Institute for Scientific Instruments-IfG)(IfG, 2008), low power $(30 \mathrm{~W})$, tungsten anode, $50 \mu \mathrm{m}$ diameter beam spot, and a silicon drift detector (super SDD, model X123SDD, Amptek). It is completed with two polycapillary X-ray lenses from IfG: a full-lens at the exit of the X-ray source (working distance of $7.3 \pm 0.1 \mathrm{~mm}$ and nominal focal spot diameter of $28 \mu \mathrm{m}$ FWHM at $8.40 \mathrm{keV}$ ), and a halflens at the entrance of the detector (working distance of $6.5 \pm 0.1 \mathrm{~mm}$ and a nominal focal spot diameter of $33 \mu \mathrm{m}$ FWHM at $8.40 \mathrm{keV}$ ). The Xray detector is interlocked with the half-lens through a metallic piece allowing XY movement respect to the conical support. The positions of both half-lens and SDD can be optimized in order to obtain the highest depth resolution.

The X-ray source and the X-ray detector are positioned at $45^{\circ}$ with respect to the surface of the analyzed sample. The working distance from the set-up to the sample is fixed by means of two laser diode modules (Micro LDM Laser Diode Modules model, Edmund Optics) with a beam size below $50 \mu \mathrm{m}$ at the optimum focusing position. A CMOS color camera (model EO-0413C, with $752 \times 480$ pixels) coupled to a zoom imaging lens (model VZM 1000i, with a primary magnification from 2.5x to 10x), both from Edmund Optics, are placed in front of the sample. Finally, a webcam permits a general view of the sample and safety control during the study.

All these components are fixed to an aluminum conical support made by IfG and fastened to a linear stage motor from OWIS (model LIMES 80-200-HSM) with a load capacity of $150 \mathrm{~N}$ (roughly $15 \mathrm{~kg}$ ) with a positioning precision lower than $1 \mu \mathrm{m}$.

The CXRF device can be mounted on a tripod but, in the case of large objects such as large dimension paintings, it can be mounted on a computer controlled 2D motion system (Fig. 2c). This device is able to move different scientific setups parallel to surface of the artwork. It allows for reaching a point of analysis anywhere in the painting and makes 1D, 2D and 3D study possible for CXRF, IRR and XRF techniques. In the case of the $\mu$ XRF-CONCHA, the device is set up with the OWIS Z motion motor fastened to the head support (Fig. 2c).

\subsection{GRT setup}

The experimental GRT setup (Ager et al., 2016; Moreno-Suarez et al., 2011; Ortega-Feliu et al., 2010; Respaldiza et al., 1994, 1990) consists of $\mathrm{a}^{241} \mathrm{Am}$ point gamma-source $(60 \mathrm{keV}, 3.7 \mathrm{GBq})$ of $6 \mathrm{~mm}$ diameter, properly shielded with lead and collimated to a $4 \mathrm{~mm}$ diameter beam. The transmitted gamma-rays from the source are detected with a $\mathrm{NaI}(\mathrm{Tl})$ detector surrounded by copper plates to absorb $\mathrm{Pb}$ X-rays from the shielding.

\subsection{IRR setup}

The Portable IRR device consists of an InGaAs camera (Xeva-XS-512 
(a)

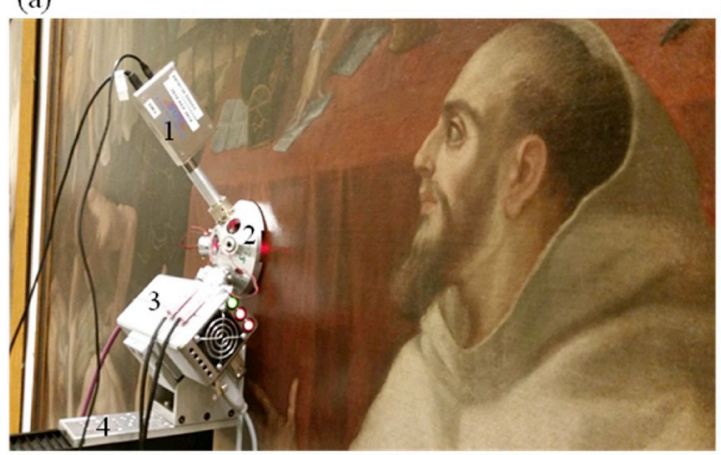

(b)

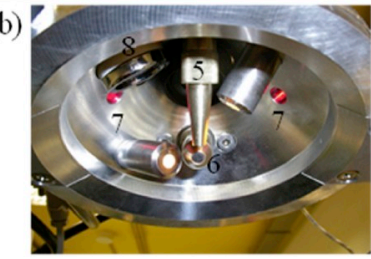

(c)

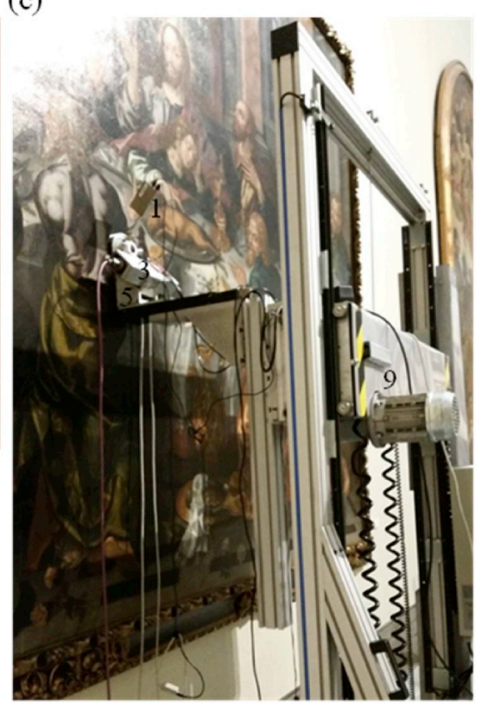

Fig. 2. Confocal $\mu X R F$ setup. (a) General view during analysis. (b) Lower view of the measuring head. (c) The 2D motion system working with the confocal $\mu X R F$ setup. (1) SSD detector. (2) Measuring head. (3) X-ray tube. (4) Motorized Z stand. (5) Half-lens of detector. (6) Full-lens of tube. (7) Fiber optics light. (9) $2 \mathrm{D}$ motion system.

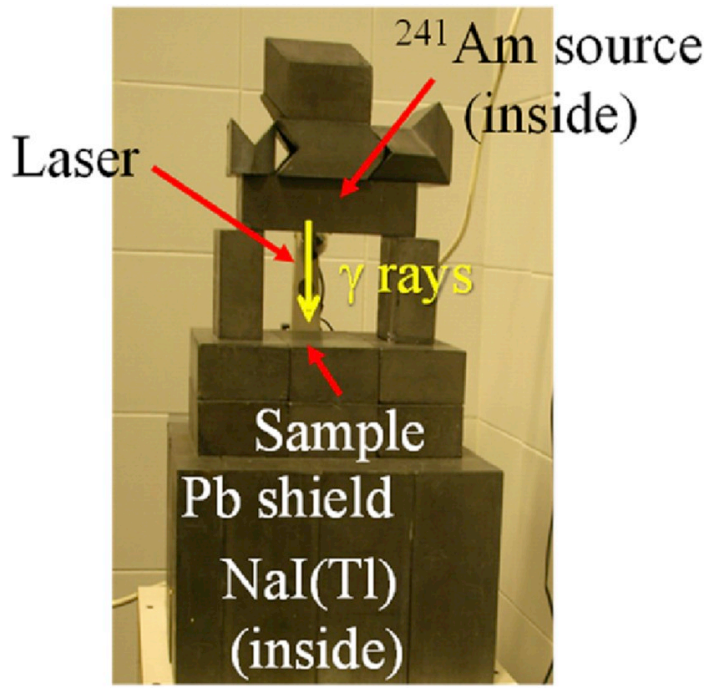

Fig. 3. Gamma ray transmission setup.

model from Xenics, $320 \times 256$ pixels resolution, Pentax lens $16 \mathrm{~mm} \mathrm{~F}$ / 1.4 ), coupled to the same $2 \mathrm{D}$ motion device and the same linear stage motor from OWIS used with the confocal $\mu$ XRF (Laclavetine, 2015). The system is programmed to automatically scan the surface of the painting and saves the matrix of IRR images. This set-up has the advantage of producing a mosaic assembly without significant deformation. It reaches more than $4 \mathrm{~m}$ in height, reaching the highest part of most paintings. Two SDI-800 W halogen lamps are normally used to ensure the IR illumination of the paintings. Fig. 3.

\subsection{Ion beam and other techniques}

Several accelerators and experimental lines available at the CNA are regularly used for applications in cultural heritage science.

The vacuum ion microprobe installed in the $3 \mathrm{MV}$ tandem accelerator focuses the beam by means of a magnetic quadrupole triplet lens up to $3 \mu \mathrm{m} \times 3 \mu \mathrm{m}$ in the case of $3 \mathrm{MeV}$ protons (Ager et al., 2017, 2013; García López et al., 2000; Respaldiza et al., 2008). A scanning coil is used to scan the surface of the sample to obtain elemental maps using PIXE and RBS techniques. Analysis by NRA, STIM and electron imaging are also possible.

In the external beam line of the $3 \mathrm{MV}$ tandem accelerator (García
López et al., 2000; Ontalba-Salamanca et al., 2001; Ontalba Salamanca et al., 2006; Ortega-Feliu et al., 2016), the proton beam can be focused up to about $70 \mu \mathrm{m}$ diameter with a precision quadrupole doublet and extracted into air through an $8 \mu \mathrm{m} \mathrm{Al}$ or $100 \mathrm{~nm} \mathrm{Si}_{3} \mathrm{~N}_{4}$ exit window. Xray detectors placed near the exit nozzle provide the corresponding spectral data for the compositional analysis of the objects by PIXE.

The Cyclone 18/9 cyclotron system at the CNA includes a high energy PIXE line (HEPIXE) that permits the study of materials with $18 \mathrm{MeV}$ protons (García López et al., 2008; Morilla et al., 2012). HEPIXE improves the identification of medium and heavy elements, reduces the target irradiation damage and increases the explored depth of analysis.

Completing the previous facilities, a $1 \mathrm{MV}$ tandetrom accelerator for AMS, a mini radiocarbon dating system for ${ }^{14} \mathrm{C}$ dating and a cobalt-60 irradiator are also available in this field. Fig. 4.

\section{Applications}

\subsection{Gold jewelry and soldering procedures: experimental archaeology}

The manufacturing procedures of ancient metal artifacts is correlated with the development of a civilization and consequently they are of special relevance in Cultural Heritage studies. However, in most cases it is mandatory or, at least, more convenient that those analyses are carried out both non-destructively and in situ, since transport the objects could be avoided. A high-sensitivity, high-resolution portable $\mu \mathrm{XRF}$ system is therefore very useful for the in-situ characterization of

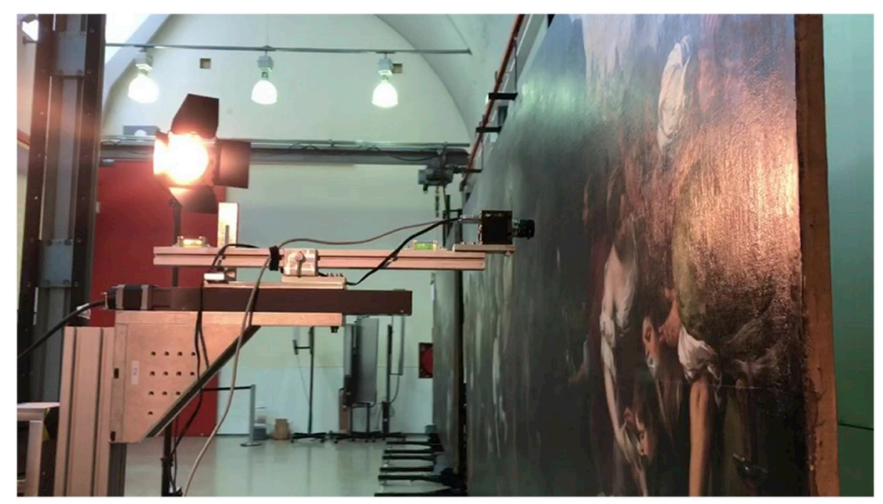

Fig. 4. The IRR setup, with the camera mounted on the motorized linear stage and attached to the $2 \mathrm{D}$ motion system. 


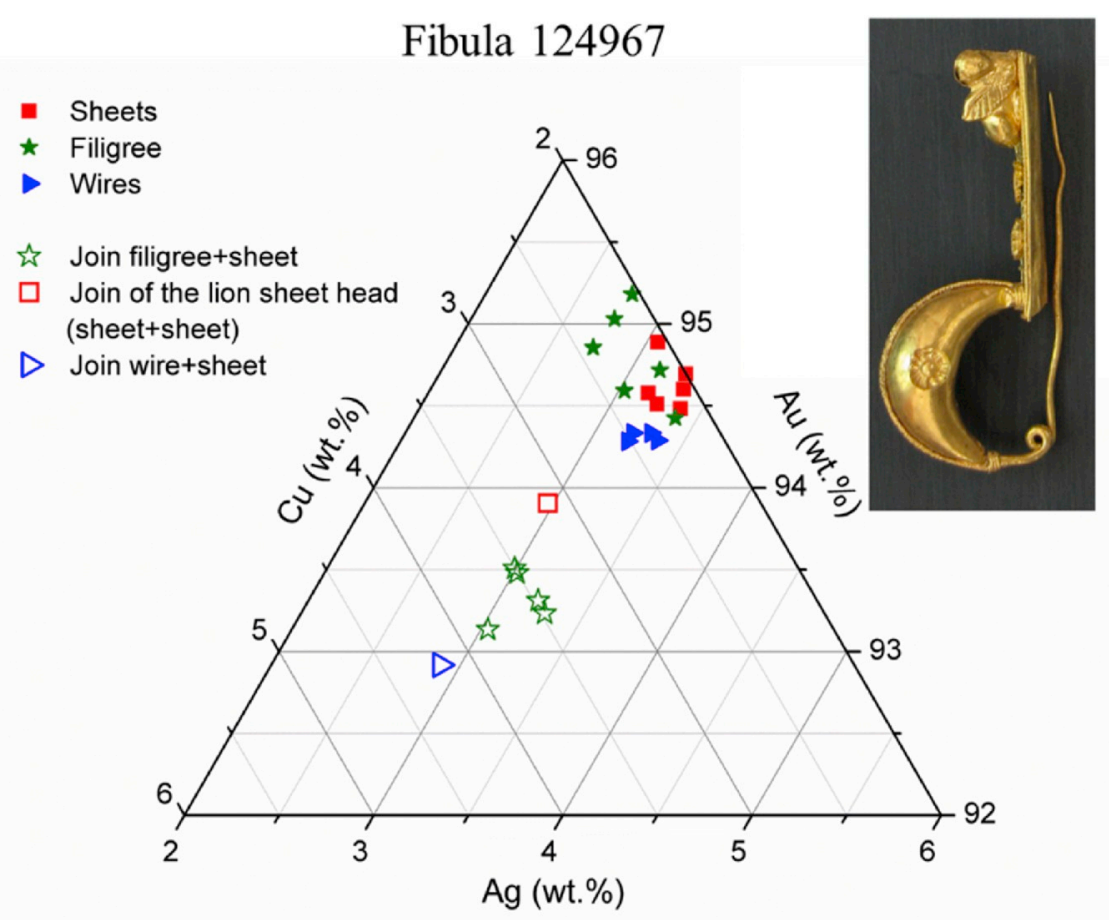

Fig. 5. $\mu$ XRF results of the joining areas of Fibula 124967. Concentration of major elements (Au, $\mathrm{Ag}$ and $\mathrm{Cu}$ ) of the items and their soldering points.

ancient jewels, such as Tartesic and Etruscan gold jewels.

Tartesic and Etruscan civilizations were coeval, and their jewelries show similar features and materials. Two jewels dating back to the Etruscan Orientalizing period were analyzed to identify the soldering techniques and compared with the soldering methods used by the Tartesic reported the results of the $\mu$ PIXE analyses of the Ecija plaque, previously performed by some of the authors (Bandera et al., 2007).

The $\mu$ XRF results of an Etruscan fibula are shown in Fig. 5 (Scrivano et al., 2017c). The different parts composing the object (sheet, wire, filigree) and the soldering areas (filigree + sheet, sheet + sheet, wire + sheet) were analyzed. By comparison of the experimental points reported in the graph, an increase of $\mathrm{Cu}$ is evident, together with a decrease of $\mathrm{Au}$, while no significant change in the $\mathrm{Ag}$ composition is observed. This is a clear indication of the solid-state diffusion bonding, a method largely used by Etruscan goldsmiths.

In Fig. 6 the results of the $\mu$ PIXE analyses of the Ecija plaque (Bandera et al., 2007) are reported. The data from the Tartesic plaque point out the use of different soldering techniques in the diverse parts of the jewel. In general, brazing is the most frequently observed soldering method in these jewels, while autogenous welding is detected in few cases. Based on the experience gained in the study of Tartesic jewels, no evidence of solid-state diffusion bonding has been found.

In order to support the results obtained by $\mu \mathrm{XRF}$, it is possible to reconstruct the ancient soldering and welding processes by means of experimental archaeology. Different gold alloys have been produced and three types of metal-joining methods have been reproduced following ancient recipes (Bostock and Riley, 1855; Caley, 1926): solidstate diffusion bonding with copper salt, brazing and autogenous welding. The content of $\mathrm{Au}, \mathrm{Ag}$ and $\mathrm{Cu}$ within the soldering or welding areas was quantified also by $\mu \mathrm{XRF}$. For example, when brazing is applied, the linear scanning performed with the portable $\mu$ XRF device (Fig. 7) shows an increase in $\mathrm{Cu}$ and $\mathrm{Ag}$ and a decrease in $\mathrm{Au}$ in the soldering zone, allowing the reduction of the fusion temperature of the soldering alloy. The results found for the other two methods are also compatible with the behavior showed in the welding and soldering areas of the Estruscan and Tartesic gold objects analyzed by $\mu \mathrm{XRF}$ (Scrivano et al., 2017a, 2013).

\subsection{Silver surface enrichment in ancient coins}

Silver surface enrichment if usually found in archaeological silvercopper alloys, either intentional or fortuitous. For instance, copper could be leached from the surface during corrosion and cleaning treatments, resulting in an apparent silver surface enrichment. The most used non-destructive techniques are surface techniques, so when fineness is to be determined, the results may be misleading since they may not be representative of the bulk composition of the alloy.

Several non-destructive approaches have been traditionally proposed to provide reliable bulk compositional data, in the usual case where the objects cannot be cross-sectioned to access the core. The combination of PIXE or XRF with gamma-ray transmission (GRT) was successfully applied to the analysis of archaeological bronzes in previous works by some of the authors (Moreno-Suarez et al., 2011; Ortega-Feliu et al., 2010; Respaldiza et al., 1994, 1990). This method is based on the correction of the elemental composition obtained by surface analysis (PIXE, XRF) with the information obtained with a nondestructive volume technique such as GRT, in order to get the bulk composition.

In this case, the surface concentrations of a set of silver roman coins, denarii and victoriati (1st to 3rd centuries CE) obtained by XRF (Ager et al., 2013) were corrected by means of GRT measurements and the results were compared with the concentrations obtained by direct $\mu \mathrm{XRF}$ analysis and $\mu$ PIXE of cross-sections of the coins (Ager et al., 2016; Moreno-Suárez et al., 2015). Elemental maps obtained by $\mu$ PIXE are useful to find evidences of surface enrichment and to estimate the thickness of the enriched layers. Fig. 8 shows Ag and $\mathrm{Cu} \mu$ PIXE maps $\left(2.5 \times 2.5 \mathrm{~mm}^{2}\right)$ of two different coins: a denarius and a victoriatus. The denarius presents a homogeneous composition (97.8 wt $\%$ Ag$1.4 \mathrm{wt} \% \mathrm{Cu}$ ) without clear signs of surface enrichment.

In contrast, the victoriatus presents a silver-enriched surface layer, $250 \mu \mathrm{m}$ thick with an average composition of $89.5 \mathrm{wt} \% \mathrm{Ag}-9.8 \mathrm{wt} \% \mathrm{Cu}$. The core composition is $56.7 \mathrm{wt} \% \mathrm{Ag}-42.5 \mathrm{wt} \% \mathrm{Cu}$. Consequently, the concentration of silver shows that the denarius analyzed was made of high purity silver whereas the victoriatus were made of debased silver.

The GRT correction method is based on the hypothesis that one of the elements is affected by surface corrosion in a different way than the 


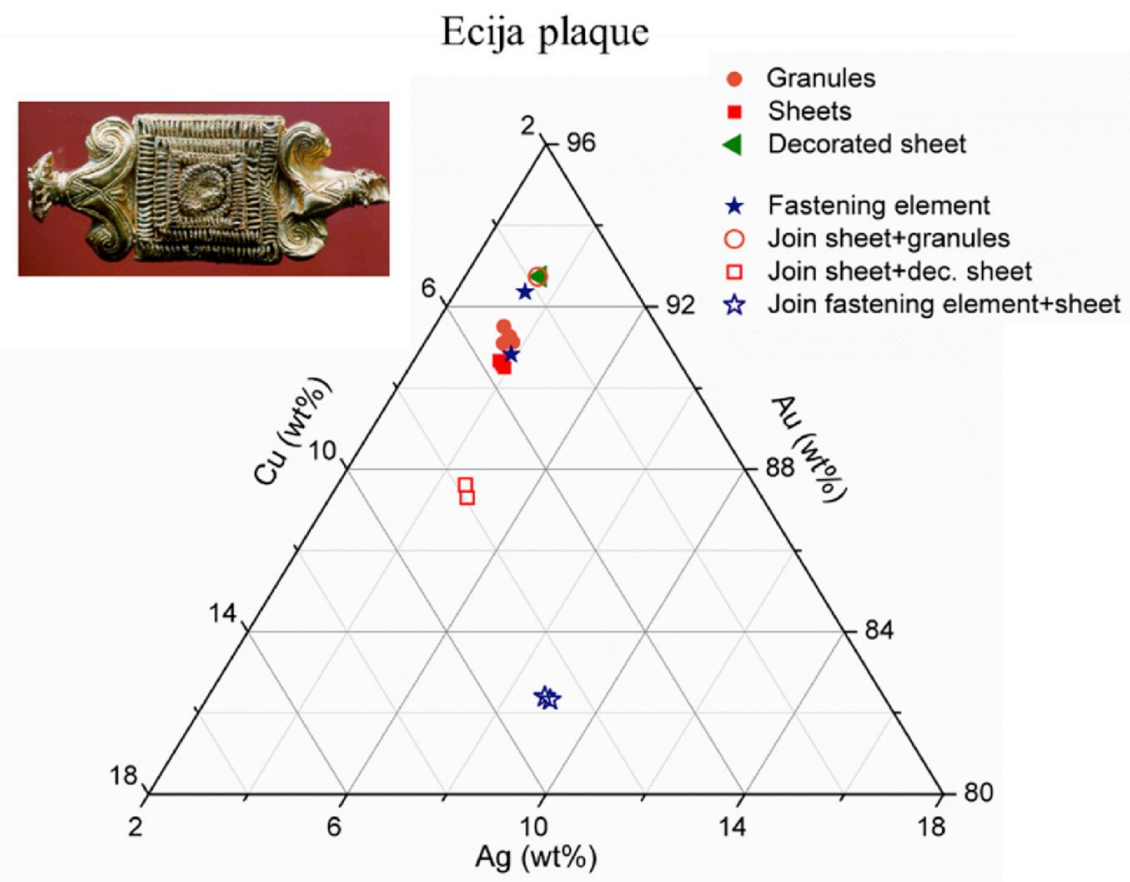

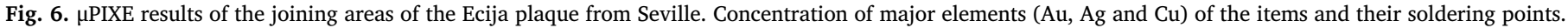

rest of them. The correction is obtained measuring the mass attenuation coefficient $\mu$ of the sample by GRT and calculating theoretical mass attenuation coefficient of the rest of the elements not affected by corrosion using the surface concentrations obtained by PIXE or XRF. In this case, $\mathrm{Cu}$ can be considered as the element being affected preferentially by corrosion and subsequent loss to the environment. Therefore, after the correction calculations by GRT (Table 1), the concentrations of the major elements, $\mathrm{Ag}$ and $\mathrm{Cu}$, were found to be in good agreement with the bulk composition obtained by direct analysis of the cut cross-sections of the coins. For surface enriched coins, $\mathrm{Ag}$ and $\mathrm{Cu}$ corrected concentrations tend to reproduce the concentrations of the bulk alloy. However, for high fineness coins ( $\mathrm{Ag}>96 \mathrm{wt} \%$ ) such as the denarius, $\mathrm{Ag}$ content is somewhat underestimated after correction since silver surface enrichment is not found, but the results show that surface composition is reliable enough in this case. Consequently, the GRT correction method is useful in the non-destructive assessment of the fineness of silver enriched coins.

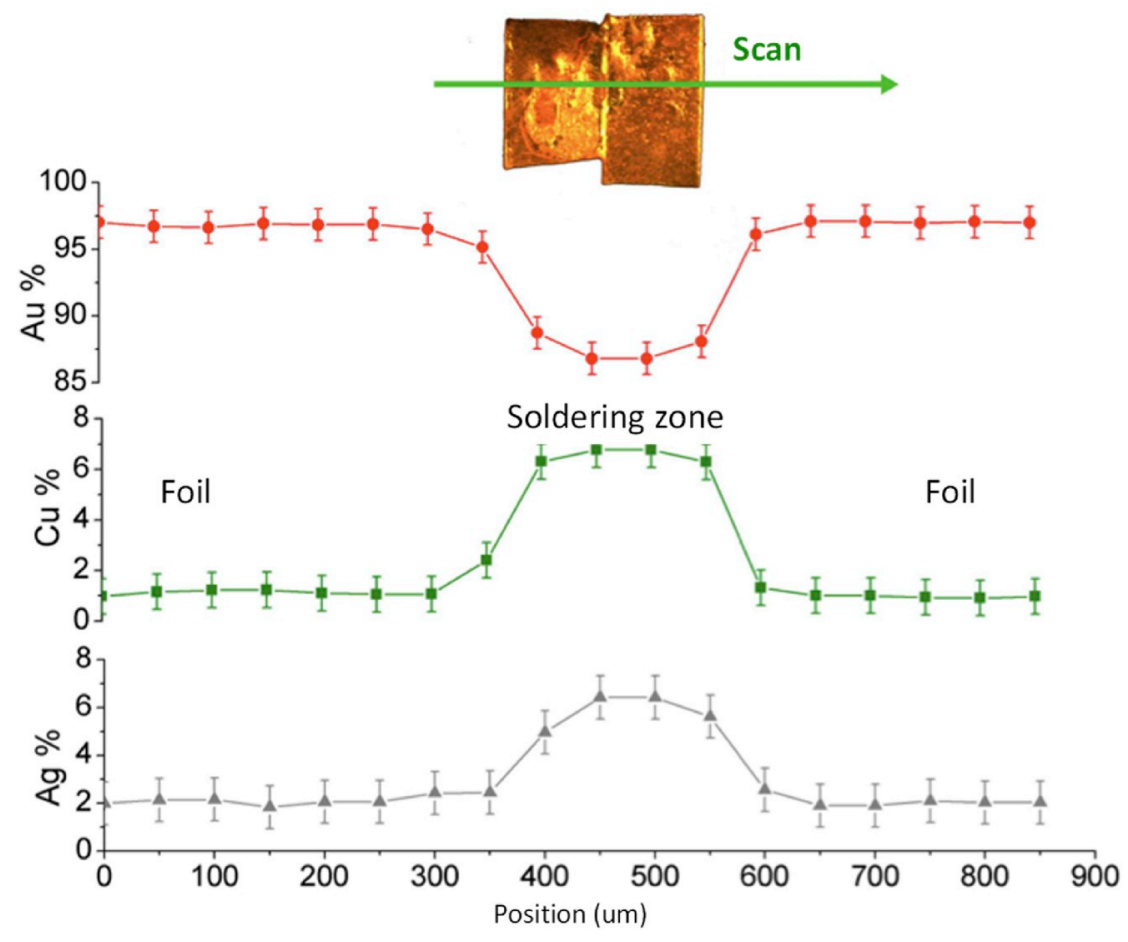

Fig. 7. $\mu \mathrm{XRF}$ analysis of two brazed foils. 
a) Denarius
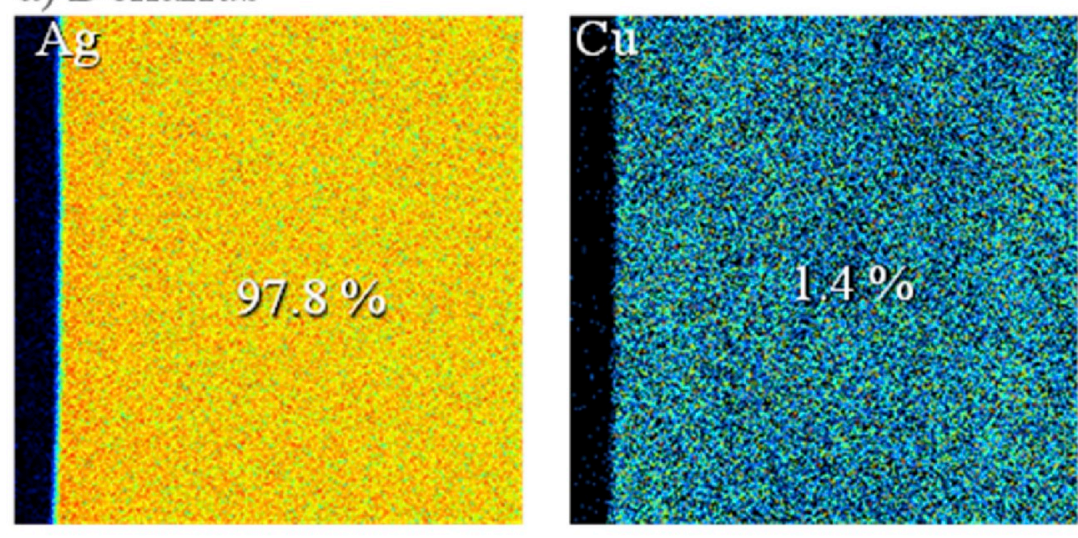

b) Victoriatus
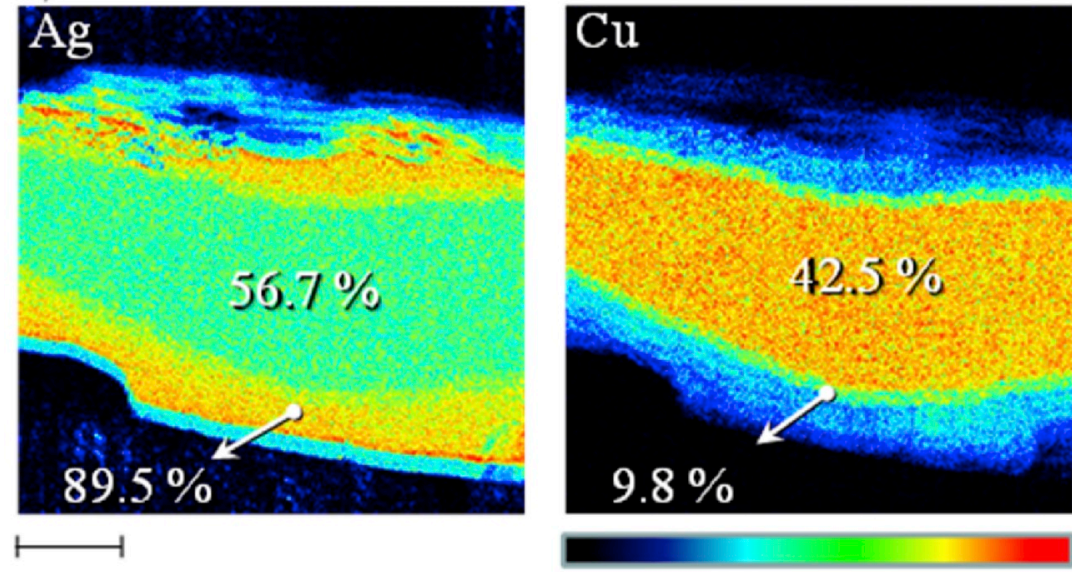

$0.5 \mathrm{~mm}$

Min

Max

Fig. 8. $\mu$ PIXE elemental maps of the cross-section of two coins: (a) denarius and (b) victoriatus (analyzed area: $2.5 \times 2.5 \mathrm{~mm}^{2}$ ).

Table 1

Mean concentrations and standard deviations of the main elements of the coins obtained by XRF (surface), corrected by GRT (corrected) and measured directly (bulk) in the cut cross-sections by $\mu \mathrm{XRF}$.

\begin{tabular}{lllll}
\hline \multirow{2}{*}{ Coin } & & \multicolumn{3}{l}{ Concentrations $(\mathrm{wt} \%)$} \\
\cline { 3 - 5 } & & $\mathrm{Ag}$ & $\mathrm{Cu}$ & $\mathrm{Au}$ \\
\hline \multirow{2}{*}{ Denarius } & Surface & $97.91(24)$ & $1.11(17)$ & $0.282(10)$ \\
& Corrected & $92.4(9.8)$ & $6.7(9.8)$ & $0.266(30)$ \\
\multirow{4}{*}{ Victoriatus } & Bulk & $97.11(26)$ & $1.66(17)$ & $0.330(18)$ \\
& Surface & $94.23(30)$ & $4.80(29)$ & $0.490(18)$ \\
& Corrected & $66.9(4.6)$ & $32.5(4.6)$ & $0.348(27)$ \\
& Bulk & $58.3(1.9)$ & $41.6(1.9)$ & \\
\hline
\end{tabular}

\subsection{Non-destructive characterization of paintings}

The analysis of paintings provides information about painting techniques, distinctive pigments, pictorial process, conservation state and may provide indications about authenticity and attribution. For this purpose, in situ non-invasive and non-destructive techniques are increasingly developed and applied especially to historical paintings. The collaboration of our group with the Museum of Fine Arts of Seville, the second-largest art museum in Spain, and the Instituto Andaluz de Patrimonio Histórico (IAPH), the central institution for cultural heritage preservation in Andalusia, provides us with a large collection of paintings and other pieces of art of the greatest cultural importance.
During the last restoration of two large Murillo's paintings $\left(3,2 \times 5,3 \mathrm{~m}^{2}\right)$ at the IAPH, several studies were carried out by means of a wide variety of analytical techniques (Križnar et al., 2018): visible and UV light inspection, IRR, macro-XRF scanning (MA-XRF), XRF, SEM-EDX and GC-MS. This enables the identification of different components of both paintings (preparation layer, pigments, binders) and also the possible presence changes or pentimenti in the paintings and underdrawings (Fig. 9). MA-XRF analyses were performed using the scanner developed at the LANDIS laboratory of CNR-IBAM and INFN-LNS in Catania (Italy)(dos Santos et al., 2018; Romano et al., 2017).

According to the analyses, the palettes used in both paintings were similar and included lead white, yellow ochre, lead-tin yellow, red ochre, vermilion, smalt, azurite, red lake, umber and bone black. A mixture of azurite and a yellow inorganic pigment was used as green. The greyish-greenish tonality of the sky and backgrounds is the result of the degradation of the original intense blue of the smalt color. Modern pigments from later interventions were also found: Prussian blue and Zinc and Titanium white. The preparation of the canvases consists of two quite thick layers made of calcite, red earth, lead white and carbon black instead of a thin priming layer. These results show the same pigment palette and painting technique found in other works made by Murillo. They are also in agreement with the technical recommendations found in painting treatises of the 17th century, such as those written by Francisco Pacheco and Antonio Palomino.

In some cases, it is also necessary to know the composition of sub- 


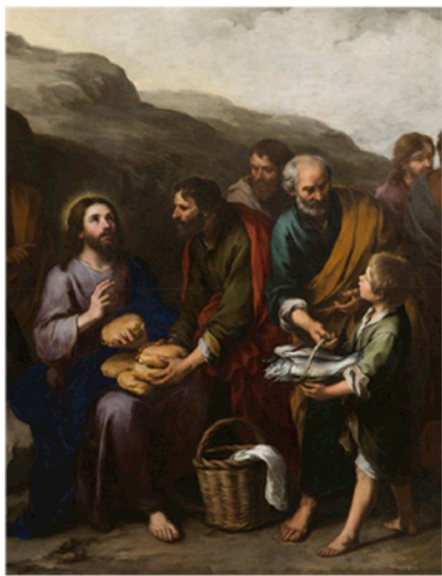

(a) Visible

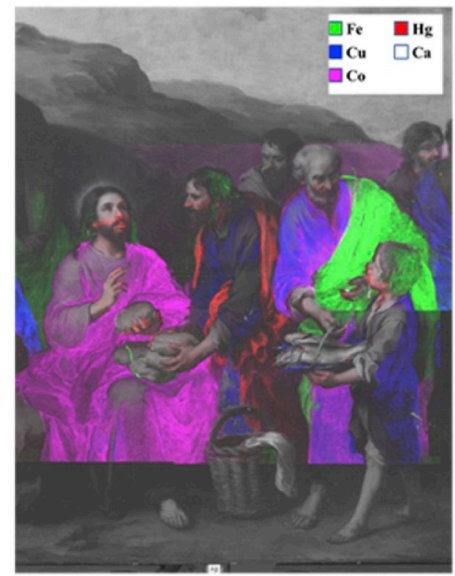

(b) MA-XRF

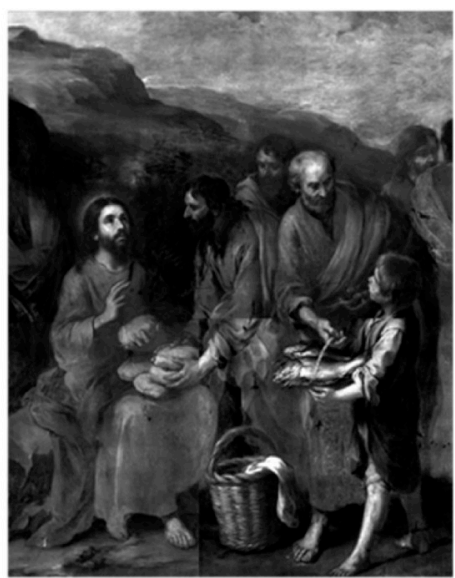

(c) $\mathrm{IRR}$

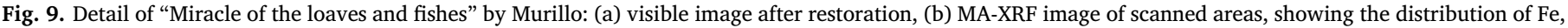
$\mathrm{Cu}, \mathrm{Co}, \mathrm{Hg}$ and $\mathrm{Ca}$, and (c) the corresponding infrared reflectography composition.

surface paint layers to find information about the working methods of the artist, the state of preservation, the effects of previous interventions or even with the goal of authentication. Confocal $\mu \mathrm{XRF}$ is currently the only non-destructive technique that allows for non-destructive depth profiling with elemental resolution that can be applied to the study of paintings, eliminating the need of sampling of standard techniques. Thus, every layer composed of inorganic pigments (ground layer, priming layer and pigment layers) can be characterized by the chemical composition.

In the case of the "Saint Peter Nolasco bids farewell to King James I of Aragon" by Alonso Vázquez, in-depth scans reveal the presence of a red priming layer (Fig. 10) and one of them shows the presence of the Ca ground layer (Laclavetine, 2015).

The lead white present in point 2 (Fig. 10) absorbs the XRF signal of the Ca ground layer. In the case of point 1 , the pigment layer and the priming layer are defined by the same chemical element $(\mathrm{Fe})$ so both layers cannot be discriminated.

\subsection{Lustre glazed islamic ceramics}

Besides XRF techniques, IBA are also used in archaeological samples, especially when a depth profile is necessary for the interpretation of the manufacture procedures. One example is the characterization of some Islamic ceramics from the Alcazaba de Almería (Spain), glazed with $\mathrm{Pb}$ and $\mathrm{Sn}$ white enamel and decorated with metallic shine or lustre made with $\mathrm{Cu}$ and $\mathrm{Ag}$ nanoparticles. The reconstruction of the manufacturing procedure could be done using RBS technique with $2 \mathrm{MeV}$ protons on sample 16743 (Fig. 11). The metallic layer is about $140 \mathrm{~nm}$ thick over the white enamel and below $\mathrm{Pb}$ and $\mathrm{Sn}$ enamel of only $30 \mathrm{~nm}$ thick (Ortega-Feliu et al., 2018).

\section{Conclusions}

In this work we have summarized the most recent advances in the techniques and methodologies that we have developed and used at the CNA in the field of cultural heritage science. It shows how the use of nuclear analysis techniques are especially interesting because of the non-destructive nature, high sensitivity and great inter-complementarity, which allows obtaining in many cases a complete analytical information on the objects under study without the need of sampling.

We have presented some examples of the use of these techniques in very different types of objects, paying special attention to how the combination of several of these techniques can sometimes surpass the main limitations of some of them (near-surface analysis, low sensitivity for light elements, lack of depth resolution, etc.).

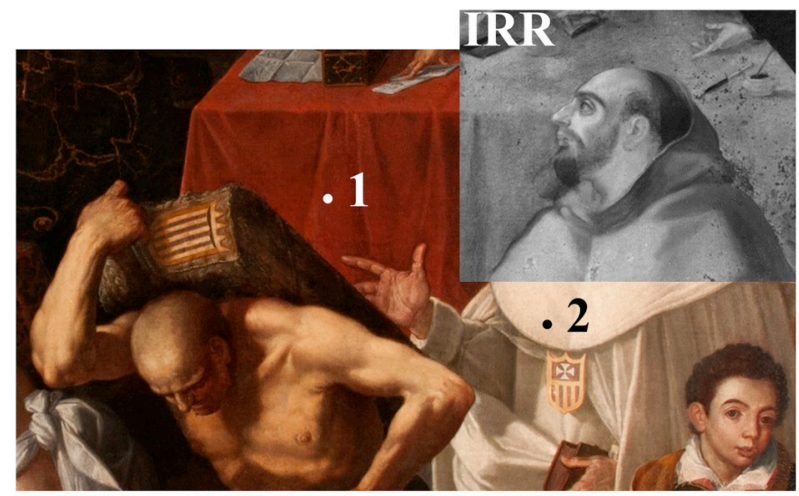

(a)

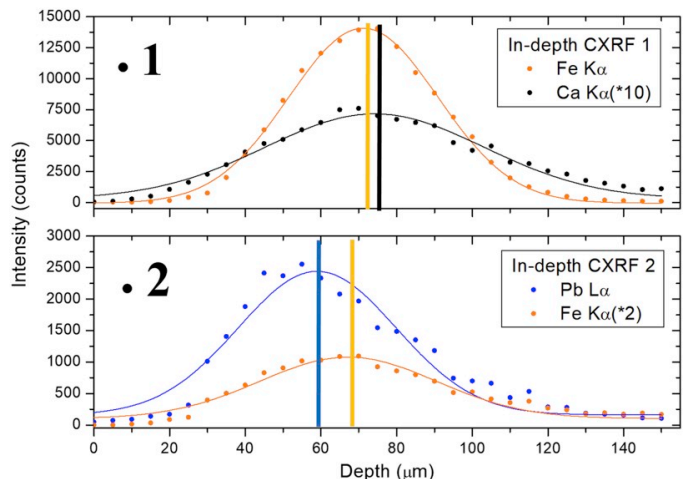

(b)

Fig. 10. Confocal XRF analysis of "Saint Peter Nolasco bids farewell to King James I". (a) Visible and IRR images showing the points of analysis. (b) CXRF elemental depth profiles. 


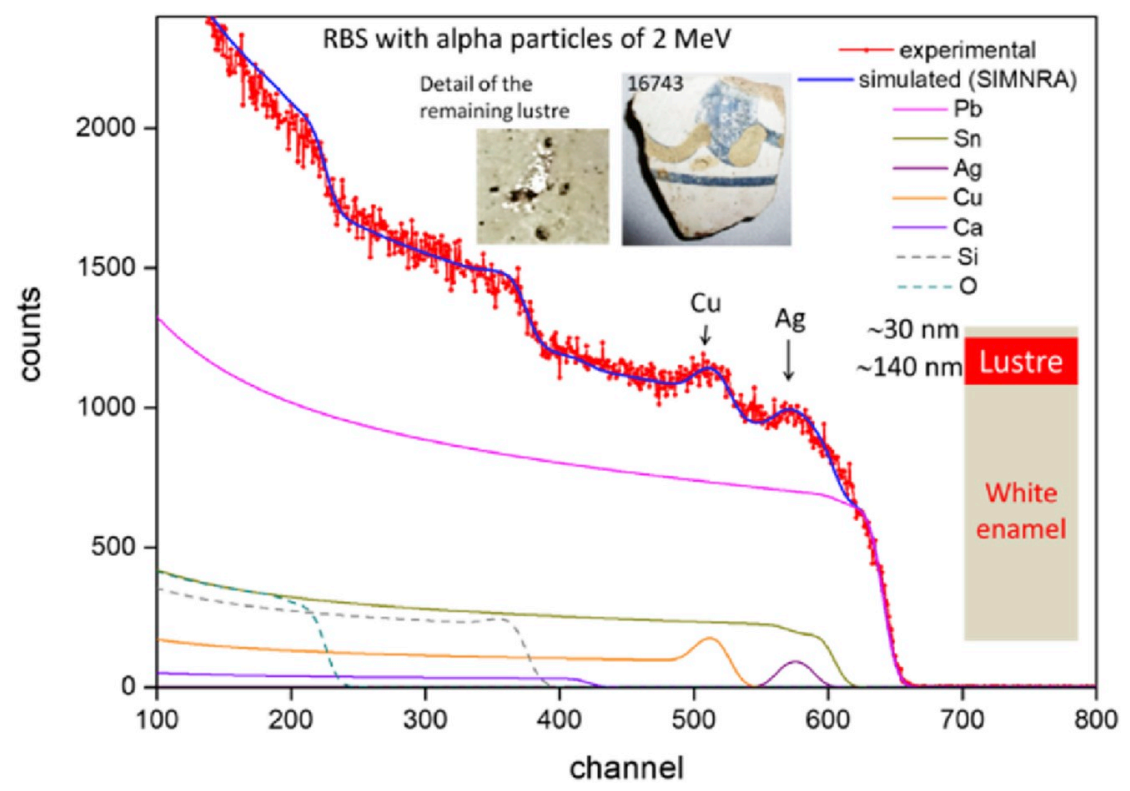

Fig. 11. RBS spectrum acquired with $2 \mathrm{MeV}$ alpha particles and simulation of a lustre glazed Islamic ceramics sample.

\section{Acknowledgements}

Work partially supported by projects HAR2012-33002 and HAR2015-67113-P from the Spanish Ministry of Science and Innovation, and project P09-HUM4544from the Junta de Andalucía. S. Scrivano and I. Ortega-Feliu acknowledge the financial support from the "V Plan Propio de Investigación" of the University of Seville. The authors wish to thank María Auxiliadora Gómez-Morón, Lourdes Núñez and Rocío Magdaleno from the IAPH, Dr. Claudia Caliri, from the INFN, and Dr. Francesco Paolo Romano from the CNR (Catania, Italy), Dr Kilian Laclavetine from the C2RMF (France), Dr. M. Ángeles Ontalba from Universidad de Extremadura and finally Dr. Antonio Paúl, Prof. Maria Luisa de la Bandera and Prof. Francisca Chávez from Universidad de Sevilla. We would also like to thank, in general, all the cultural institutions within our domestic environment and their staff: Department of Prehistory and Archeology of the University of Seville, Archaeological Museum of Sevilla, Andalusian Institute of Historical Heritage (IAPH), Museum of Fine Arts of Seville, Seville Cathedral and Archbishop's Palace, among others. Most of the cases of study in this work are the result of a fruitful collaboration with all of them during all these years.

\section{References}

Ager, F.J., Ferretti, M., Grilli, M.L., Juanes, D., Ortega-Feliu, I., Respaldiza, M.A., Roldán, C., Scrivano, S., 2017. Reconsidering the accuracy of X-ray fluorescence and ion beam based methods when used to measure the thickness of ancient gildings. Spectrochim. Acta Part B At. Spectrosc. 135, 42-47. https://doi.org/10.1016/j.sab.2017.06.017.

Ager, F.J., Gómez-Tubío, B., Paúl, A., Gómez-Morón, A., Scrivano, S., Ortega-Feliu, I., Respaldiza, M.A., Gomez-Tubio, B., Paul, A., Gomez-Moron, A., Scrivano, S., OrtegaFeliu, I., Respaldiza, M.A., Gómez-Tubío, B., Paúl, A., Gómez-Morón, A., Scrivano, S., Ortega-Feliu, I., Respaldiza, M.A., 2016. Combining XRF and GRT for the analysis of ancient silver coins. Microchem. J. 126, 149-154. https://doi.org/10.1016/j.microc. 2015.12.017.

Ager, F.J., Moreno-Suárez, A.I., Scrivano, S., Ortega-Feliu, I., Gómez-Tubío, B., Respaldiza, M.A., Moreno-Suarez, A.I., Scrivano, S., Ortega-Feliu, I., Gomez-Tubio, B., Respaldiza, M.A., Moreno-Suárez, A.I., Scrivano, S., Ortega-Feliu, I., GómezTubío, B., Respaldiza, M.A., Moreno-Suarez, A.I., Scrivano, S., Ortega-Feliu, I., Gomez-Tubio, B., Respaldiza, M.A., 2013. Silver surface enrichment in ancient coins studied by micro-PIXE. Nucl. Instruments Methods Phys. Res. Sect. B-Beam Interact. with Mater. Atoms 306, 241-244. https://doi.org/10.1016/j.nimb.2012.12.037.

Bandera, M., de la, Gómez Tubío, B., Ontalba Salamanca, M.A., Ortega Feliu, I., Respaldiza Galisteo, M.A., 2007. Caracterización de orfebrería antigua mediante técnicas nucleares de análisis no destructivos. Santuola XIII 113-128.

Bostock, J., Riley, H.T., 1855. Pliny the Elder, the Natural History. Perseus at Tufts.

Caley, E.R., 1926. The Leyden Papyrus X. An English translation with brief notes. J. Chem. Educ. 3, 1149. https://doi.org/10.1021/ed003p1149. dos Santos, H.C., Caliri, C., Pappalardo, L., Catalano, R., Orlando, A., Rizzo, F., Romano, F.P., 2018. Real-time MA-XRF imaging spectroscopy of the Virgin with he Child painted by Antonello de Saliba in 1497. Microchem. J. 140, 96-104. https://doi.org/ 10.1016/j.microc. 2018.04.015.

García López, J., Ortega-Feliu, I., Morilla, Y., Ferrero, A., 2008. The new Cyclone 18/9 beam transport line at the CNA (Sevilla) for high energy PIXE applications. Nucl. Instrum. Methods Phys. Res. Sect. B Beam Interact. Mater. Atoms 266, 1583-1586. https://doi.org/10.1016/J.NIMB.2007.11.035.

García López, J., Ager, F.J., Barbadillo Rank, M., Madrigal, F.J., Ontalba, M.A., Respaldiza, M.A., Ynsa, M.D., García-Lopez, J., Ager, F.J., Rank, M.B., Madrigal, F.J., Ontalba, M.A., Respaldiza, M.A., Ynsa, M.D., 2000. CNA: the first accelerator-based IBA facility in Spain. Nucl. Instruments Methods Phys. Res. Sect. B-Beam Interact. with Mater. Atoms 161, 1137-1142. https://doi.org/10.1016/S0168-583X(99) 00702-8.

IfG, 2008. IfG - Institute for Scientific Instruments GmbH(Rudower Chaussee 29/31, D12489 Berlin). [WWW Document]. URL www.ifg-adlershof.de.

Križnar, A., Ager, F.J., Caliri, C., Romano, F.P., Respaldiza, M.Á., Gómez-Morón, M.A., Núñez, L., Magdaleno, R., 2018. Study of Two Large-dimension Murillo's Paintings by Means of Macro X-ray Fluorescence Imaging, Point X-ray Fluorescence Analysis, and Stratigraphic Studies. X-Ray Spectrom., vol. 2990. https://doi.org/10.1002/xrs. 2990.

Laclavetine, K., 2015. Non-destructive Techniques for in Situ Studies of Easel Paintings: Development and Application of a Confocal X-Ray Micro-fluorescence System. PhD. Thesis. Universidad de Sevilla.

Laclavetine, K., Ager, F.J., Arquillo, J., Respaldiza, M.Á., Scrivano, S., 2016. Characterization of the new mobile confocal micro X-ray fluorescence (CXRF) system for in situ non-destructive cultural heritage analysis at the CNA: $\mu$ XRF-CONCHA. Microchem. J. 125, 62-68. https://doi.org/10.1016/j.microc.2015.11.013.

Moreno-Suárez, A.I., Ager, F.J., Scrivano, S., Ortega-Feliu, I., Gómez-Tubío, B., Respaldiza, M.A., 2015. First attempt to obtain the bulk composition of ancient silver-copper coins by using XRF and GRT. Nucl. Instrum. Methods Phys. Res. Sect. B Beam Interact. Mater. Atoms 358, 93-97. https://doi.org/https://doi.org/10.1016/j. nimb.2015.05.038.

Moreno-Suarez, A.I., Gomez-Tubio, B., Respaldiza, M.A., Chaves, F., Ortega-Feliu, I., Ontalba-Salamanca, M.A., Ager, F.J., 2011. Combining non-destructive nuclear techniques to study Roman leaded copper coins from Ilipa (II-I centuries BC). Nucl Instruments Methods Phys. Res. Sect. B-Beam Interact. with Mater. Atoms 269, 3098-3101. https://doi.org/10.1016/j.nimb.2011.04.077.

Morilla, Y., Jiménez-Ramos, M.C., García López, J., Labrador, J.A., Palomo, F.R., OrtegaFeliu, I., 2012. Developing the IBA equipment to increase the versatility of the CNA. Nuclear Instruments and Methods in Physics Research, Section B: Beam Interactions with Materials and Atoms. North-Holland, pp. 218-221. https://doi.org/10.1016/j. nimb.2011.07.079.

Ontalba-Salamanca, M.A., Ager, F.J., Ynsa, M.D., Tubio, B.M.G., Respaldiza, M.A., GarcíaLopez, J.G., Fernandez-Gomez, F., de la Bandera, M.L., Grime, G.W., 2001. External microbeam set-up at the CNA (Sevilla) and its application to the study of Tartesic jewellery. Nucl. Instruments Methods Phys. Res. Sect. B-Beam Interact. with Mater. Atoms 181, 664-669.

Ontalba Salamanca, M.Á., Gómez-Tubío, B., Ortega-Feliu, I., Respaldiza, M.Á., Luisa de la Bandera, M., Ovejero Zappino, G., Bouzas, A., Gómez-Morón, A., 2006. Externalbeam PIXE spectrometry for the study of Punic jewellery (SW Spain): the geographical provenance of the palladium-bearing gold. Nucl. Instrum. Methods Phys. Res. Sect. B Beam Interact. Mater. Atoms 249, 622-627. https://doi.org/10.1016/j. nimb.2006.03.172. 
Ortega-Feliu, I., Gómez-Tubío, B., Cáceres, Y., Respaldiza, M.Á., 2018. Characterization of glaze ceramics from the archaeological site of La Alcazaba, Almería (Spain). Microchem. J. 138, 72-81. https://doi.org/10.1016/J.MICROC.2017.12.022.

Ortega-Feliu, I., Gómez-Tubío, B., Respaldiza, M.A., Capel, F., Nieto-Prieto, X., 2016. Xray and gamma-ray based spectroscopic analysis of a millefiori Roman glass fragment: degradation of sunken glass from a shipwreck. J. Anal. At. Spectrom. 31, 773-779. https://doi.org/10.1039/C5JA00443H.

Ortega-Feliu, I., Moreno-Suarez, A.I., Gomez-Tubio, B., Ager, F.J., Respaldiza, M.A., Garcia-Dils, S., Rodriguez-Gutierrez, O., Moreno-Suárez, A.I., Gómez-Tubío, B., Ager, F.J., Respaldiza, M.A., García-Dils, S., Rodríguez-Gutiérrez, O., 2010. A comparative study of PIXE and XRF corrected by Gamma-Ray Transmission for the non-destructive characterization of a gilded roman railing. Nucl. Instruments Methods Phys. Res. Sect. B-Beam Interact. with Mater. Atoms 268, 1920-1923. https://doi.org/10.1016/ j.nimb.2010.02.102

Respaldiza, M.A., Ager, F.J., Carmona, A., Ferrer, J., García-León, M., García-López, J., García-Orellana, I., Gómez-Tubío, B., Morilla, Y., Ontalba, M.A., Ortega-Feliu, I., 2008. Accelerator-based research activities at "Centro nacional de Aceleradores", Seville (Spain). Nucl. Instrum. Methods Phys. Res. Sect. B Beam Interact. Mater. Atoms 266, 2105-2109. https://doi.org/https://doi.org/10.1016/j.nimb.2008.02. 080.

Respaldiza, M.A., Gómez-Tubío, B.M., del Junco, A.S., Barranco, F., Sáiz-Jiménez, C. 1994. Non-destructive analysis of archaeological bronzes by nuclear techniques. Nucl. Instrum. Methods Phys. Res. Sect. B Beam Interact. Mater. Atoms 89, 109-113. https://doi.org/10.1016/0168-583x(94)95156-x.

Respaldiza, M.A.A., Barranco, F., Gómez-Camacho, J., Gómez-Tubío, B.M.M., RuizDelgado, M.M.M., 1990. Combining PIXE and XRF with gamma-ray transmission to get accurate analysis of archaeological bronzes. Nucl. Instrum. Methods Phys. Res. Sect. B Beam Interact. Mater. Atoms 50, 226-230. https://doi.org/10.1016/0168583x(90)90359-3.

Romano, F.P., Caliri, C., Nicotra, P., Di Martino, S., Pappalardo, L., Rizzo, F., Santos, H.C., 2017. Real-time elemental imaging of large dimension paintings with a novel mobile macro X-ray fluorescence (MA-XRF) scanning technique. J. Anal. At. Spectrom. 32, 773-781. https://doi.org/10.1039/c6ja00439c.

Scrivano, S., Gomez-Tubio, B., Ortega-Feliu, I., Ager, F.J., Moreno-Suarez, A.I., Respaldiza, M.A., de la Bandera, M.L., Marmolejo, A., Gómez-Tubío, B., Ortega-Feliu, I., Ager, F.J., Moreno-Suárez, A.I., Respaldiza, M.A., de la Bandera, M.L., Marmolejo, A., 2013. Identification of soldering and welding processes in ancient gold jewelry by micro-XRF spectroscopy. X Ray Spectrom. 42, 251-255. https://doi.org/10.1002/xrs 2482.

Scrivano, S., Gómez Tubío, B., Ortega-Feliu, I., Ager, F.J., Paul, A., Respaldiza, M.A., 2017a. Compositional and microstructural study of joining methods in archaeological gold objects. X Ray Spectrom. 46, 123-130. https://doi.org/10.1002/xrs.2738.

Scrivano, S., Ortega-Feliu, I., Gómez-Tubío, B., Ager, F.J., de la Bandera, M.L., Respaldiza, M.A., Ontalba-Salamanca, M.A., 2017b. Non-destructive micro-analytical system for the study of the manufacturing processes of a group of gold jewels from "El Carambolo" treasure. Radiat. Phys. Chem. 130, 133-141. https://doi.org/10.1016/j. radphyschem.2016.08.008.

Scrivano, S., Ruberto, C., Gómez-Tubío, B., Mazzinghi, A., Ortega-Feliu, I., Ager, F.J., Laclavetine, K., Giuntini, L., Respaldiza, M.A., 2017c. In-situ non-destructive analysis of Etruscan gold jewels with the micro-XRF transportable spectrometer from CNA. J. Archaeol. Sci. Reports 16, 185-193. https://doi.org/10.1016/j.jasrep.2017.09.032. 